\title{
Progress of the technique of coal microwave desulfurization
}

\author{
Xiuxiang Tao $\cdot$ Ning Xu $\cdot$ Maohua Xie $\cdot$ Longfei Tang
}

Received: 28 March 2014/Revised: 16 May 2014/Accepted: 18 May 2014/Published online: 15 August 2014

(C) The Author(s) 2014. This article is published with open access at Springerlink.com

\begin{abstract}
With the advantages of its fast speed, effective and moderate controllable conditions, desulfurization of coal by microwave has become research focus in the field of clean coal technology. Coal is a homogeneous mixture which consists of various components with different dielectric properties, so their abilities to absorb microwaves are different, and the sulfur-containing components are better absorbers of microwave, which makes them can be selectively heated and reacted under microwave irradiation. There still remain controversies on the principle of microwave desulfurization at present, thermal effects or non-thermal effects. The point of thermal effects of microwave is mainly base on its characters of rapidly and selectly heating. While, in view of non-thermal effect, direct interactions between the microwave electromagnetic field and sulfur containing components are proposed. It is a fundamental problem to determine the dielectric properties of coal and the sulfur-containing components to reveal the interaction of microwave and sulfur-containing compounds. However, the test of dielectric property of coal is affected by many factors, which makes it difficult to measure dielectric properties accurately. In order to achieve better desulfurization effect, the researchers employ methods of adding chemical additives such as acid, alkali, oxidant, reductant, or changing the reaction atmosphere, or combining with other methods such as magnetic separation, ultrasonic and microorganism. Researchers in this field have also put forward several processes, and have obtained a number of patents. Obscurity of microwave desulfurization mechanism, uncertainties in qualitative and quantitative analysis of sulfur-containing functional groups in coal, and the lack of special microwave equipment have limited further development of microwave desulfurization technology.
\end{abstract}

Keywords Microwave desulfurization · Dielectric properties · Microwave effects · Clean coal

\section{Introduction}

Coal is one of the main energy sources in China, accounting for $70 \%$ of the primary energy. About $80 \%$ of coal is used for combustion as fuel and generating electricity at present, causing serious air pollution. According to statistics, $\mathrm{SO}_{2}$ emissions were 21.851 million tons in 2010 , of which $85 \%$ is from the combustion of coal. And

X. Tao $(\bowtie) \cdot$ N. Xu $\cdot$ M. Xie $\cdot$ L. Tang

Key Laboratory of Coal Processing and Efficient Utilization of Ministry of Education, School of Chemical Engineering and

Technology, China University of Mining and Technology,

Xuzhou 221116, China

e-mail: taoxx163@163.com at the same time, the sulfur in the coal also enters into the coal chemical products, affecting the quality of coke, syngas, and a carbon material and corroding the production equipment (He et al. 2001; Gao et al. 2010).

There are more high-sulfur coal reserves in China, $15 \%$ of which is mid-high-sulfur and high-sulfur coal containing more than $2 \%$ sulfur content, mainly distributed in Guizhou, Chongqing and Sichuan provinces. The main form of sulfur in coal is pyrite sulfur, followed by organic sulfur, and sulfate sulfur the lowest. According to statistics, among high-sulfur coal whose average sulfur content is $3.76 \%$, pyrite sulfur content is $1.61 \%$, organic is $1.04 \%$ and sulfate is $0.11 \%$ (Luo et al. 2005; Zhang 2005).

At present, many methods have been used for coal desulfurization before combustion by physical, chemical 
and biological ways. While conventionally physical desulfurization method is economic and process simple, it can only remove inorganic sulfur from coal, not organic sulfur (Tao et al. 2006; Temel et al. 2010). Although both inorganic and organic sulfur can be removed by chemical method which needs harsh conditions such as acid, alkali, high temperature and high pressure, the macromolecular structure and properties of coal are destroyed, and the high processing cost also affects its technical competitiveness (Alam et al. 2009; Mursito et al. 2011). Despite of its mild reaction condition and low cost, biological desulfurization is less stable, time-consuming and less controllable, so it still stays in the laboratory stage (Yang et al. 2013). Coal desulfurization by microwave radiation is a new coal sulfur removal method in recent years and in the field of clean coal technology it has great potential for development and application prospects. As a energy field, Microwave can heat substance fastly, uniformly and selectively. It has been used widely in many fields including mineral leaching (AlHarahsheh and Kingman 2004; Chen et al. 2011), wastewater treatment (Lin et al. 2009; Remya and Lin 2011), environmental engineering and oil sand and petroleum upgrading (Jones et al. 2002; Mutyala et al. 2010). With the increasing emphasis on environmental issues, the application of microwave technology in the field of clean coal technology has attracted attention of experts (Zavitsanos and Blriler 1978; Meikap et al. 2005; Kalra 2006; Lester et al. 2006; Sahoo et al. 2011; Royaei et al. 2012; Ge et al. 2013; Xia et al. 2013).

Coal is an inhomogeneous compound, and the sulfurcontaining components are better absorber of microwave energy than coal matrix, which leads to selectly heating and chemical changes to the sulfur-containing components accordingly. And when the sulfur-containing components are heated and activated quickly, the temperature of coal matrix still remains low. In such a case, the sulphur in coal may be removed without damage to the coal properties.

\section{Principles and characteristics of microwave desulfurization}

Microwaves are electromagnetic waves with frequencies between 0.3 and $300 \mathrm{GHz}$ and wavelengths ranging from $1 \mathrm{~mm}$ to $1 \mathrm{~m}$. The frequencies used for microwave heating are $915 \mathrm{MHz}$ and $2.45 \mathrm{GHz}$, whereas $2.45 \mathrm{GHz}$ is much more common for civil use and industrial application.

At present, there are numerous studies on microwave desulfurization of coal, but the basic understanding of interaction between the high-frequency electromagnetic radiation and coal and sulfur-containing constituents, and the exact reasons of sulfur bond breaking caused by microwaves irradiation still remains unclear.
The microwave desulfurization removes the sulfur in coal primarily using selective heating of microwaves with little damage to the major structure of coal. Currently, two mechanisms and effects of microwave desulfurization are proposed in the field of microwave chemistry (Sun et al. 2000; Xia et al. 2004; de la Hoz et al. 2005; Huang and Yang 2006; Arnaud 2009; Chen et al. 2009; Huang et al. 2009; Horikoshi and Serpone 2011): thermal effect and non-thermal effect.

\subsection{Thermal effect}

Microwave thermal effect refers to a phenomenon where the microwave energy is converted into thermal energy after being absorbed by matter manifested by the total loss of microwave energy in the matter (Kappe et al. 2005). In microwave field, polar molecules of the dielectric medium move regularly in the electric field direction instead of its original disorderly thermal motion. And the thermal motion and interference and obstruction of intermolecular interaction force play a role similar to internal friction and convert the electric field energy absorbed into thermal energy enabling the temperature of dielectric medium to rise accordingly.

The thermal effects of microwaves are mostly associated with their capacity to convert electromagnetic energy to thermal energy at a particular temperature and frequency and the capacity may be measured with the loss tangent tan $\delta$ of the matter (Didier 2006):

$\tan \delta=\varepsilon^{\prime \prime} / \varepsilon^{\prime}$

where $\varepsilon^{\prime}$ is the dielectric loss of matter, indicates the efficiency of the matter in converting electromagnetic energy to thermal energy; $\varepsilon^{\prime}$ is the dielectric constant, indicates the matter polarization capacity and the larger its value is, the stronger coupling effect on microwaves will be (Ma et al. 2011).

In this viewpoint, it is believed that the cause of increasing reaction rate is purely a thermal/kinetic effect, i.e. a very high temperature will be achieved quickly when microwaves are acting on polar materials. The microwave irradiation does not affect the pre-exponential factor $A$ and the energy term (activation energy Ea) in Arrhenius' equation $k=A \exp (-E \mathrm{a} / \mathrm{RT})$, and only the temperature term changes.

The relationship between the coal dielectric properties and microwave energy absorbed may be derived from Maxwell's equations (Thostenson and Chou 1999; Clark et al. 2000):

$P=2 \pi \varepsilon_{0} f E^{2} \varepsilon^{\prime \prime}$

where $P$ is power absorbed $(W) ; f$ is frequency applied $(\mathrm{Hz}) ; E$ is electric field intensity $(V / m) ; \varepsilon_{0}$ is vacuum absolute dielectric constant; $\varepsilon^{\prime \prime}$ is dielectric loss. 
This formula shows that the coal absorption power has a positive relationship with its dielectric loss under a given microwave frequency and microwave field intensity. Coal is an inhomogeneous compound, and the dielectric losses of various constituents are differently leading to an uneven distribution of internal energy in coal under microwave radiation. The dielectric loss value of pyrite in coal is much larger than that of coal substance, which enables the pyrite to be heated selectively (Uslu and Atalay 2003; Han et al. 2013). As a result, microcosmic hotspots are thus formed and activated quickly. And then an in situ pyrolytic reaction occurred to the pyrite.

The Fe-S bonds in pyrite molecules can be induced to break down by the high temperature of microwave radiation and then combine with the surrounding activated $\mathrm{H}, \mathrm{O}$ and CO in coal (Weng and Wang 1992; Uslu et al. 2003; Waters et al. 2007). These pocesses can form sulfur-containing gases such as $\mathrm{H}_{2} \mathrm{~S}, \mathrm{COS}, \mathrm{SO}_{2}$, and the reactions are as below:

$$
\begin{aligned}
& \mathrm{FeS}_{2}+(\mathrm{H}-\text { coal }) \rightarrow \mathrm{Fe}_{1-x} \mathrm{~S}+\mathrm{H}_{2} \mathrm{~S} \uparrow \quad 0<x \leq 0.125 \\
& \mathrm{Fe}_{1-x} \mathrm{~S}+(\mathrm{H}-\mathrm{coal}) \rightarrow \mathrm{FeS}+\mathrm{H}_{2} \mathrm{~S} \uparrow \\
& \mathrm{FeS}_{2}+(\mathrm{O}-\text { coal }) \rightarrow \mathrm{Fe}_{1-x} \mathrm{~S}+\mathrm{SO}_{2} \uparrow \\
& \mathrm{Fe}_{1-x} \mathrm{~S}+(\mathrm{O}-\text { coal }) \rightarrow \mathrm{FeS}+\mathrm{SO}_{2} \uparrow \\
& \mathrm{FeS}_{2}+(\mathrm{CO}-\text { coal }) \rightarrow \mathrm{Fe}_{1-x} \mathrm{O}+\mathrm{COS} \uparrow \\
& \mathrm{Fe}_{1-x} \mathrm{~S}+(\mathrm{CO}-\text { coal }) \rightarrow \mathrm{FeS}+\mathrm{COS} \uparrow
\end{aligned}
$$

Thus, pyrite changes into pyrrhotine $\left(\mathrm{Fe}_{1-x} \mathrm{~S}\right)$ and troilite (FeS),

$$
\mathrm{FeS}_{2} \rightarrow \mathrm{Fe}_{1-x} \mathrm{~S} \rightarrow \mathrm{FeS}
$$

And the changes of pyrite was found to progress from left to right as irradiation time increased.

Pyrrhotine $\left(\mathrm{Fe}_{1-\mathrm{x}} \mathrm{S}\right)$ and troilite $(\mathrm{FeS})$ can be removed by acid washing, since they are soluble in acid (Jorjani et al. 2004; Zhao et al. 2011). And pyrrhotite is a highly magnetic mineral which can be easily removed from the coal via a low intensity magnetic separation (Uslu et al. 2003).

At the same time, such pyrolytic reactions happened to the organic sulfur in coal (Zavitsanos and Blriler 1978; Jorjani et al. 2004).

$($ Organic sulfur - coal $)+(\mathrm{H}-$ coal $) \rightarrow$ coal $+\mathrm{H}_{2} \mathrm{~S} \uparrow$

$($ Organic sulfur - coal $)+(\mathrm{O}-$ coal $) \rightarrow$ coal $+\mathrm{SO}_{2} \uparrow$

$($ Organic sulfur - coal $)+(\mathrm{CO}-\mathrm{coal}) \rightarrow \operatorname{coal}+\mathrm{COS} \uparrow$

The pyrite is usually found fine distributed and in small amount in coal matrix, and its heat absorbed from the microwave is apt to dissipated by the surrounding material, which results in the temperature is not high enough for the reactions. And in order to increase the temperature and accelerate the reactions, agents with large dielectric loss (such magnetite, caustic alkali) are usually used (Yang and Ren 1988; Uslu and Atalay 2003).

The addition of such agents can increase the dielectric loss and thus increasing the temperature of the system, and some of them can even react with sulfur-containing components. Taking $\mathrm{NaOH}$ as an example which has a large dielectric loss value, it can not only increase the temperature of the system but also react with pyrite (partial organic sulfur) as follows (Zhao et al. 1996; Mohamed 2008; Sheng 2013; Zhou et al. 2013b),

$2 \mathrm{FeS}_{2}+6 \mathrm{NaOH} \rightarrow \mathrm{NaFeO}_{2}+4 \mathrm{Na}_{2} \mathrm{~S}+2 \mathrm{H}_{2} \mathrm{O}$

$\mathrm{O}_{2} \mathrm{R}-\mathrm{SH}+2 \mathrm{NaOH} \rightarrow \mathrm{R}+\mathrm{Na}_{2} \mathrm{~S}+\mathrm{H}_{2} \mathrm{O}$

$\mathrm{R}-\mathrm{S}-\mathrm{R}^{\prime}+2 \mathrm{NaOH} \rightarrow \mathrm{R}^{\prime} \mathrm{OH}+\mathrm{ROH}+\mathrm{Na}_{2} \mathrm{~S}$

In order to accelerate desulfurization, the oxidizing additive hydrogen peroxide-acetic acid is usually used for microwave desulfurization. The generation of oxidized intermediate $\mathrm{OH}^{+}$is accelerated under the effect of microwave (Zhao et al. 2002; Chen 2013). And it can react with the activated pyrite (partial organic sulfur) as follows:

$$
\begin{aligned}
& \mathrm{CH}_{3} \mathrm{COOH}+\mathrm{H}_{2} \mathrm{O}_{2} \rightarrow \mathrm{CH}_{3} \mathrm{COOOH}+\mathrm{H}_{2} \mathrm{O} \\
& \mathrm{CH}_{3} \mathrm{COOOH}+\mathrm{H}^{+} \rightarrow \mathrm{CH}_{3} \mathrm{COOH}+\mathrm{OH}^{+} \\
& \text {Pyrite incoal }+\mathrm{OH}^{+} \rightarrow \text { sulfate, methanesulfonicacid } \\
& \text { Organicsulfur incoal }+\mathrm{OH}^{+} \rightarrow \text { Solubleorganicsulfide }
\end{aligned}
$$

And moreover different mineral constituents in the same microwave field are heated to different extent due to their different dielectric properties. And in addition, different mineral constituents have different thermal expansion coefficients and may cause thermal strain on their interfaces and fissures accordingly, which will be helpful for desulfurization agent to penetrate into the coal (Hayashi et al. 1990; Marland et al. 1998). And the response of sulphide minerals to microwaves is much stronger than that of coal matrix and quartz. Pyrites tightly embedded in the coal will tend to have fissures under microwave irradiation to allow the monomers to be dissociated, which will improve the reaction between pyrite and desulfurization agent (Marland et al. 2000).

In summary, the point of thermal effects of microwave is mainly base on its characters of rapidly and selectly heating.

\subsection{Non-thermal effect}

At present, the non-thermal effect proposed is mostly based on the results of direct interaction between the microwave electromagnetic field and reactant molecules (de la $\mathrm{Hoz}$ et al. 2005; Kappe et al. 2005; Huang and Yang 2006; Huang et al. 2009). If the orientation effect of dipole molecules occurs or the microwave frequency approximates the 
molecular rotational frequency, microwaves energy absorbed by polar molecules will freely exchange with molecular average kinetic energy and change the pre-exponential factor $A$ or activation energy in Arrhenius' equation; some also believe that microwaves may cause molecular vibration and generate "large chemical bond" resonance under energy of microwaves under specific frequency bands, which will result in selective depolymerization of sulfurcontaining constituents or fission of sulphur chemical bonds in coal due to electromagnetic resonance effect.

In the study on the microwave desulfurization process of vulcanized rubber, Tang et al. (2006) discover that when the vulcanized rubber samples were irradiated by microwave for 10 and $20 \mathrm{~s}$ respectively, their temperatures are 26 and $41{ }^{\circ} \mathrm{C}$, and the sulfur chemical bonds in rubber rupture. It is believed that the damage to the cross-linked network of the vulcanized rubber is largely attributable to the non-thermal effect of microwaves.

However, it is generally accepted that the microwaves can not cause any changes to the chemical bonds on account of relatively-low frequency and quantum energy of microwaves. Nevertheless, if they act in an unstable process where the old bonds are rupturing and new bonds are forming, the bond energy is reduced substantially and may be influenced by microwave photons (Sun et al. 2000; Yang and Huang 2006; Chen et al. 2009). Some scholars also examine two groups, M1 and M2, bonded by chemical bonds from the viewpoint of quantum mechanics. And M1 is deemed as a harmonic oscillator moving in M2 gravitational potential well and it is found through numerical calculation that the ratio between field intensity acting force and random acting force is 10:7 and the time for M2 to escape from M1 gravitational potential well significantly relates to the microwave field intensity.

As for the non-thermal effect, there exist many disputes currently (Antonio and Deam 2007; de la Hoz et al. 2007; Reddy et al. 2013), especially no final conclusion has yet been reached on the research results due to inaccuracy of material temperature measurement in the microwave field (Schmink and Leadbeater 2009; Gomaa et al. 2013). The non-thermal effect has been seldom studied in the field of microwave desulfurization of coal.

In the field of clean coal technology, people tend to study the microwave thermal effect resulted from the characteristics of microwave dielectric heating, e.g. the microwave energy is able to promote in situ pyrite pyrolysis, solvent overheating, and the generating of hotspots of desulfurization additives, etc. (Wang and Yang 1994; Elsamak et al. 2003; Al-Harahsheh et al. 2006).

During the process of microwave desulfurization of coal, the energy of microwaves is absorbed selectively by sulphur-containing constituents in coal, based on different characteristics of responses to microwave irradiation and their energy is converted into heat thereby achieving desulfurization. The microwave desulfurization of coal not only relates to the methods used but also closely relates to the physical and chemical structures of sulphur-containing constituents in coal.

\section{Study on dielectric properties of coal and sulphur- containing constituents}

There is almost no research on the relationship between the electromagnetic resonance effect and the sulphur removal by microwave and definite cognition of the optimum working frequency for desulphurization. Research on the dielectric properties of coal and sulphurcontaining constituents is the basic problem of the practice of coal desulfurization with microwave, which aims to find out the optimum working frequency under which the sulphur-containing constituents have the strongest absorptive capacity and reveal the chemical and physical mechanism of responses of sulphur-containing constituents to microwave.

\subsection{Test methods for dielectric properties}

Dielectric property refers to the nature of storing and losing electrostatic energy under the effect of electric field. Based on the principle of measurement, the test methods for dielectric properties of coal and sulphur-containing constituents can be roughly divided into (Dong 1990; Wang 2006; Tian et al. 2002; Santra 2005; Agilent 2006; Nelson 2010): parallel-plate capacitance method, transmission reflection method (See Fig. 1), coaxial probe method, freespace method (Fig. 2), resonant cavity method (Fig. 3) etc. An LCR meter or dielectric impedance meter is usually used in the parallel-plate capacitance method and a vector network analyzer is usually used for measurement in the

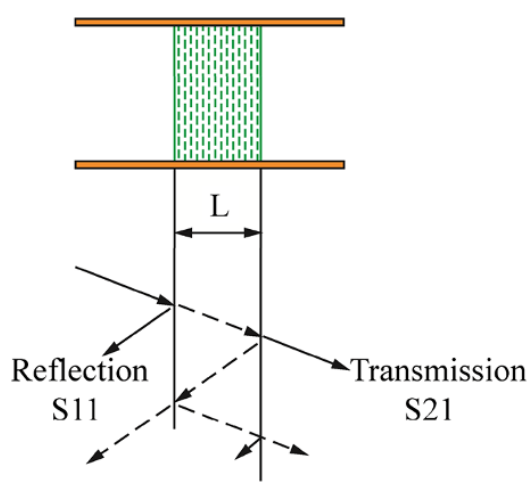

Network analyzer

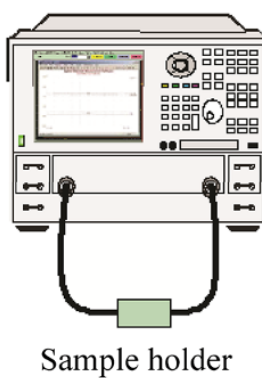

Fig. 1 Schematic diagram of transmission reflection method 


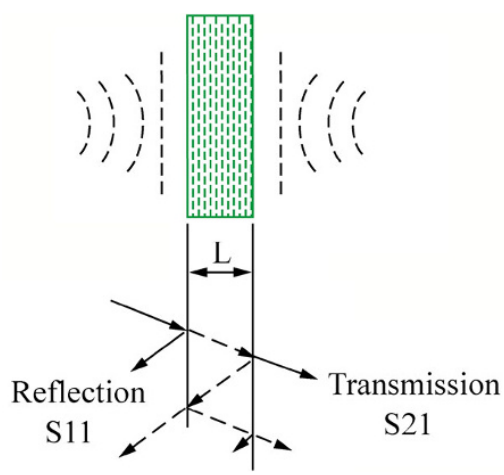

Network analyzer

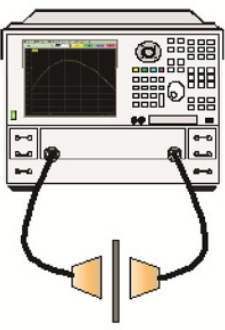

Sample holder

Fig. 2 Schematic diagram of free-space method

transmission reflection method, coaxial probe method, free-space method and resonant cavity method. The parallel-plate capacitance method has high test accuracy but it has a low frequency range (HP); the transmission reflection method, coaxial probe method, and free-space method can be used to measure broadband but they tend to measure media with low loss inaccurately (Venkatesh and Raghavan 2005; Krupka 2006). The resonant cavity method is especially suitable for test for low-loss medium in terms of test accuracy, but the test is typically conducted at a certain frequency point (Venkatesh and Raghavan 2005).

\subsection{Test of complex dielectric constant of coal}

Complex permittivity refers to energy loss inside the substance due to hysteresis effects of dielectric conductance and dielectric polarization under the electric field. The real part is the permittivity commonly referred to and the imaginary part is the dielectric loss factor.
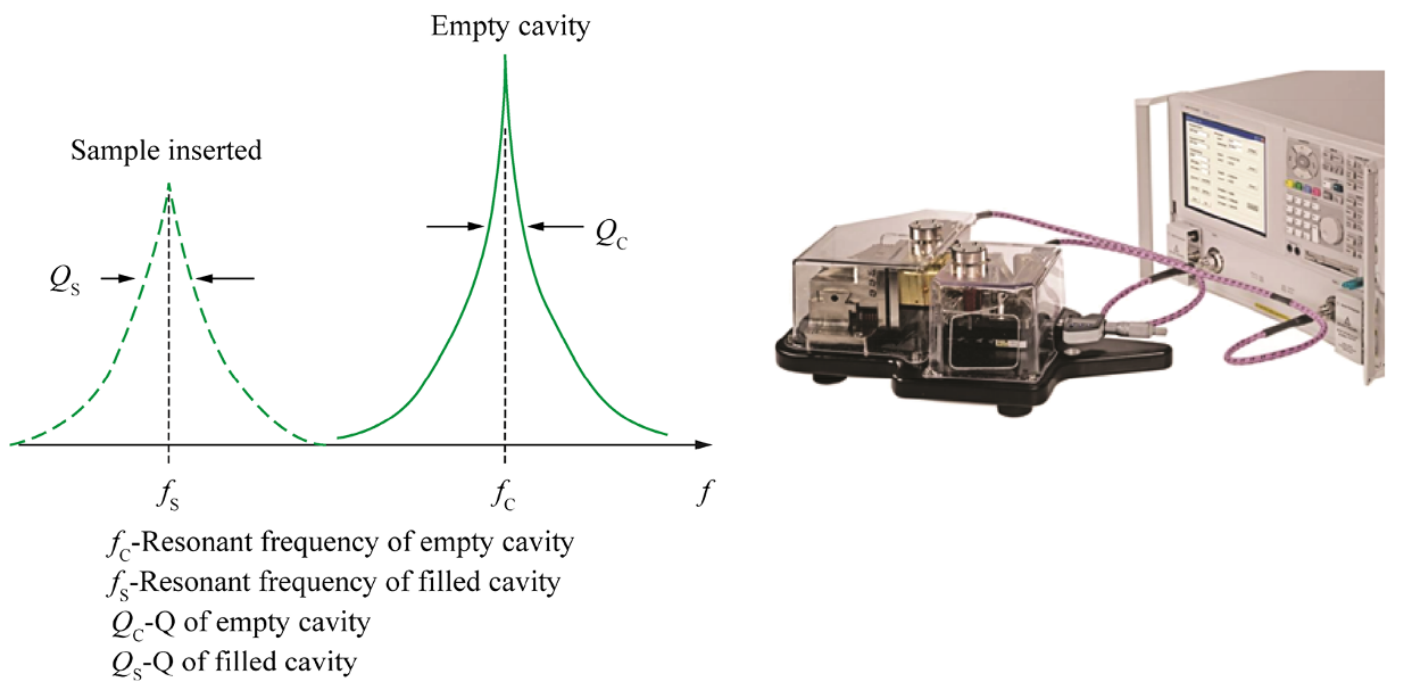

Fig. 3 Schematic diagram of resonant cavity method

Coal is a non-homogeneous compound and its dielectric properties depend on coal rank, moisture, mineral composition, porosity, test temperature, frequency, etc. (Balanis et al. 1980; Marland et al. 2001; Forniés-Marquina et al. 2003). Thus, it is hard to accurately measure the dielectric properties and the test results obtained by different scholars are usually inconsistent.

Coal dielectric properties are closely associated with coal rank and moisture. Generally speaking, coal with a low rank has a greater $\varepsilon^{\prime}$ and $\varepsilon^{\prime \prime} ; \varepsilon^{\prime}$ and $\varepsilon^{\prime \prime}$ decreased gradually with the increase of coalification and reached the smallest for bituminous coal with a medium metamorphic degree; subsequently, $\varepsilon^{\prime}$ and $\varepsilon^{\prime \prime}$ started to increase again with the increase of metamorphic degree (Misra et al. 1991; Meng 2001; Zubkova and Prezhdo 2006; Hakala et al. 2011). For dry coal samples, $\varepsilon^{\prime}$ and $\varepsilon^{\prime \prime}$ varies little from lignite to young anthracite and subsequently increased rapidly with the rising coal ranks (Chatterjee and Misra 1990; Wang 1982).

The reasons of presence of the above rules are that (Xu et al. 1998; Chu 2011), coal with a low coalification degree has a number of polar oxygen-bearing functional groups in their macromolecular structure and it has a great amount of moisture. Polar functional groups and moisture decrease with the increase of the metamorphic degree subsequently. And at the anthracite stage, the macromolecular aromatic laminar structure increased rapidly and intramolecular $\pi$ orbits overlapped, the activity range of electrons enlarged, and free electrons increased thus rapidly increasing the permittivity.

At the same time, the dielectric properties of coal were also associated with test temperatures and frequencies. In conclusion, the coal permittivity usually decreases with the rise of test frequency (Hakala et al. 2011; Cai 2013; 
Boykov 2006). As a result of the intrinsic composition and structure of coal and the complexity of reactions during heating, the effect of temperature on dielectric properties are very complicated thus leading to a slight difference in the test results obtained by different scholars (Feng and Chen 2007; Li et al. 2012; Peng et al. 2012).

In addition to this, the dielectric properties of coal are also associated with such factors as minerals, porosity etc. (Xiao 1985; Xu 2005; Gao et al. 2007; Cai 2013).

\subsection{Responses of coal and sulphur-containing constituents to microwaves}

Coal is an inhomogeneous compound, and the dielectric constants of individual constituents are different. It is a fundamental problem to determine the dielectric properties of coal and the sulfur-containing components, so as to reveal the rules that how microwave effects sulfur-containing compounds thus leads to the breakage of chemical bond of sulfur.

Chatterjee and Misra (1990) have pointed out that the dielectric constants of dry-basis coal, pyrite and minerals (excluding pyrite) are 3.0, 7.0 and 4.6 respectively. And the difference of dielectric property between coal and pyrite were reported by many other researchers.

Marland (Marland et al. 2001) has pointed out typical average heating rates of $1.0{ }^{\circ} \mathrm{C} / \mathrm{s}$ for pyrite are achieved compared to $0.2{ }^{\circ} \mathrm{C} / \mathrm{s}$ for coals irradiated at a power of $650 \mathrm{~W}$ and a frequency of $2.45 \mathrm{GHz}$.

Forniés-Marquina et al. (2003) has shown that when the sulphur content was higher than $4 \%$ the coal relaxation frequency would decreased with the increase of sulphur content, which might contribute to microwave absorption.

Cai Chuanchuan (2013) tested the dielectric properties of a high-sulfur coal (the content of organic sulfur is $1.5 \%$ ) and a low-sulfur coal (the content organic sulfur is $0.3 \%$ ). The results has shown that the high-sulfur coal has high relative dielectric constant. The relative dielectric constant mainly reflected the intensity of the response of polar groups under the electromagnetic field, and the high-sulfur coal contains more polar molecules which have a strong response to microwave. At frequency of $16 \mathrm{GHz}$, the dielectric loss factor of high-sulfur coal is significantly higher than that of low-sulfur coal, but at other frequencies there is little difference. At the same time, he also measured the dielectric properties of such sulfur-containing model compounds as phenyl disulfide, dibenzothiophene, diphenyl sulfone, diphenylsulfoxide, octadecanethiol et al. The results has shown that the measured model compounds have strong absorption of microwave under high frequencies (9-11 GHz) and also have a significant dielectric loss under low frequencies $(0.5-2 \mathrm{GHz})$. Hence, for its deep penetration depth, microwave of low-frequencies $(0.5-2 \mathrm{GHz})$ is more interesting, and it provides reference for the future research on the optimal frequencies at which the sulfurcontaining components have the greatest dielectric response to the electromagnetic wave.

The research achievements on dielectric properties of coal and the sulfur-containing compounds, have a certain guiding significance for choosing frequency band and selecting desulfuration agents. Microwave desulfuration is a dynamic temperature-changing process during which very complex physical-chemical reactions take place. But now, it is exactly lack of research on equivalent dielectric constant of coal desulfuration system under temperaturechanging conditions.

\section{Research status of microwave desulfurization technique}

\subsection{Direct microwave desulfurization}

The microwaves are absorbed selectively and microwave energy is converted into heat quantity when the pyrite in coal is exposed to microwaves. The pyrite's capacity to absorb microwaves is more than ten times higher than that of coal; the pyrite converts into pyrrhotite with stronger magnetism under high temperature while the sulphide is released in the form of hydrogen sulfide. And the organic sulfur can also be pyrolyzed by microwave heating. Reaction assistants will not be used in this method.

Yin (2003) has studied removing the sulfur in Yima coal through microwave pyrolysis for achieving the removal rate of inorganic sulfur, $31.98 \%$ and the removal rate of organic sulfur, $6.96 \%$.

Wang and Yang (1994) pointed out that the degrees to which the pyrite is decomposed into pyrrhotite and troilite are different in the nitrogen gas environment under condition of different irradiation times. The decomposition reaction of pyrite depends largely on the reductive gases produced during coal matrix decomposition. However, on the other hand, the immobilization effect of sulphur cause a lower level of overall desulfurization of coal largely due to the fact that the sulfide gases from decomposition, such as $\mathrm{H}_{2} \mathrm{~S}, \mathrm{COS}$, are subjected to reaction with coal and generate new sulfur-containing substances different from the originals. Thus, it is helpful to effectively control the immobilization effect of the sulfur-containing gases generated for microwave pyrolysis desulfurization of coal.

Chen (2013) studied the microwave desulfurization of coal under the atmosphere of $\mathrm{N}_{2}$ and $\mathrm{H}_{2}$ respectively. It is indicated that the influences of power and time on microwave desulfurization are great, and the best reaction conditions are the microwave power $560 \mathrm{~W}$ and the irradiation time $30 \mathrm{~min}$, under which condition a high desulphurization 
rate was obtained (atmosphere of $\mathrm{N}_{2} 20.45 \%$ and atmosphere of $\mathrm{H}_{2} 24.36 \%$ ) without damage to the caking. Sulfur analysis results show that with the increase of irradiation time after $30 \mathrm{~min}$, the organic sulfur removal rate gradually decreases. The pyrite sulfur content has no obvious change under $\mathrm{N}_{2}$ atmosphere, while its removal rate is much higher under $\mathrm{H}_{2}$ atmosphere. Gas chromatographic analysis showed that: under $\mathrm{N}_{2}$ atmosphere sulfur was escaped mainly in the form of $\mathrm{H}_{2} \mathrm{~S}$, and under $\mathrm{H}_{2}$ atmosphere it was escaped in the form of $\mathrm{COS}$ and $\mathrm{SO}_{2}$.

And the patents of Kirkbride (1978, 1979), Zavitsanos (and Blriler 1978), Frank (Marhanka 1995), Zheng YH (Zheng et al. 2012), Zhou M (Zhou et al. 2013a), and Zhao et al. (2013) belong to this method too. And all these patents will be mentioned in detail in Sect. 4.3.

\subsection{Desulfurization by microwaves combined with magnetic separation}

Desulfurization of coal by magnetic separation is an effective pre-combustion physical desulfurization technique characterized by low energy consumption, simple process, cost-effectiveness, environment-friendliness etc. The more significant the magnetic difference is, the better the separation result will be. Although there exists difference in magnetism between coal matrix and coal-bearing series pyrite, the difference of magnetic susceptibility between them is not significant. The actual separation effect is not ideal and it is hard to achieve a good result even when high-gradient magnetic field separation (HGMS) is sometimes used. Therefore, strengthening the magnetism of coalbearing series pyrite is the key to remove pyritic sulphur from coal using the magnetic separation method. The magnetic susceptibility of coal-bearing series pyrite can be raised significantly through thermal treatment (Kawatra and Eisele 2001). The problem brought about by the traditional thermal treatment is that the coal matrix is also heated while the pyrite is being heated. The selective heating characteristic of microwaves can effectively solve the problem and avoid the loss of coal matrix. Uslu and Atalay (2003) and Waters et al. (2007) pointed out in their studies that the pyrite tends to convert into pyrrhotite with strong magnetism thus contributing to magnetic separation of pyrite when exposed to microwave irradiation.

The Mössbauer spectroscopy method is currently the best method to directly determine the sulphur-iron compounds. Sui et al. (2004) found, by the Mössbauer spectroscopy, that extension of irradiation time within a certain period helps conversion from pyrite to pyrrhotite. Whereas, the conversion effect is not obvious if the irradiation time exceeds a certain period due largely to the fact that the products of pyrrhotite tend to convert to troilite as irradiation time increases. So the microwave irradiation time shall be appropriately controlled accordingly. Meanwhile, both reducing particle size and addition of caustic soda are able to significantly improve the conversion effect (Rowson and Rice 1990a; Waanders et al. 2009). Cheng and Qiu (2002) have placed the coal samples mixed with $\mathrm{NaOH}$ into the microwave oven for 2 min radiation under the conditions of microwave frequency of $2.45 \mathrm{GHz}$ and power of $900 \mathrm{~W}$ and found that the ratio for pyrite converting into pyrrhotite is $24.7 \%$. And they systematically studied the process of coal microwave irradiation-magnetic separation desulfurization. Rowson and Rice (1990b) has conducted a microwave-assisted pyrite removal test under the conditions of a $500 \mathrm{~W}$ microwave power and a $2.45 \mathrm{GHz}$ frequency. The pyrite can be heated selectively but the rate of temperature increasing is not enough to enable the pyrite to convert into magnetite as a result of low output power of microwaves. The pyrite will convert into pyrrhotite under the same microwave condition when the coal samples are mixed with strong alkaline liquor $(\mathrm{KOH}$ or $\mathrm{NaOH})$. The nature of the coal does not change significantly but the removal rate of total sulfur reaches $70 \%$ when the particle size of coal dust $<0.2 \mathrm{~mm}$ and the microwave irradiation lasts for $60 \mathrm{~s}$.

\subsection{Desulfurization by microwaves combined with chemical method}

The alkali liquor is usually added to the coal samples to increase the dielectric loss of the system and thus improve the desulfurization result. And the combination of microwave radiation with oxidant (such as glacial acetic acid and hydrogen peroxide) and reducer (such hydriodic acid) are also used to remove sulphur efficiently.

\subsubsection{Desulfurization by microwaves combined with acid washing}

As mentioned above, microwave heating can induce the pyrite embedded in coal to react with the active substances around and prompt the pyrite convert into pyrrhotite and troilite which are soluble in acid solutions. Weng and Wang (1992)has found that $97 \%$ inorganic sulfur in coal can be removed by acid washing after the microwave irradiation for $10 \mathrm{~min}$ under the conditions of $1.5 \mathrm{~kW}$ microwave power, $2.45 \mathrm{GHz}$ frequency. Similarly, in Jorjani' study (2004), it is indicated that after exposed to microwave irradiation under the optimum test conditions, the bond energy between $\mathrm{C}-\mathrm{S}$ and $\mathrm{Fe}-\mathrm{S}$ in coal is weakened, which makes the bond more liable to break down by hydrogen peroxide acid washing. And it can be concluded that it is the pyritic sulphur that is removed primarily based on the FTIR analysis and the variation of peak before and after irradiation. 


\subsubsection{Desulfurization by microwaves combined with alkaline liquor}

As is mentioned in Sect. 3.2, the addition of caustic alkali can improve the efficiency of conversion of pyrite to pyrrhotite, and it will not be repeated in this section.

Yang and Ren (1988) have conducted a microwave desulfurization test using waste alkaline liquor as extracting agent and the total desulfurization rate can reach $75 \%-$ $85 \%$ after irradiating two times. Taking $\mathrm{NaOH}$ solution as leachant, Sheng et al. (2012) has conducted a microwave desulfurization test at $2.45 \mathrm{GHz}$ frequency and investigated the effects of various factors on the desulfurization. And the results show that under the optimal condition of microwave power $800 \mathrm{~W}$, irradiation time $7 \mathrm{~min}$, particle size of coal $-0.125 \mathrm{~mm}$, concentration of leachant $300 \mathrm{~g} /$ $\mathrm{L}$, liquid-solid ratio $4: 1$, the desulfurization rate reaches $52.85 \%$ and the calorific value loss of coal after treatment was $4.29 \%$. Zhao $\mathrm{H}$ et al. (2011) studied the desulfurization of coal by microwave combined with $\mathrm{NaOH}$ solution. About $1 \mathrm{~g}$ of raw coal and $80 \mathrm{ml}$ saturated $\mathrm{NaOH}$ solution were mixed together in a container, and put into the microwave reaction device with microwave power $700 \mathrm{~W}$, microwave frequency $2.45 \mathrm{GHz}$ to research the effect of radiation time on desulfurization. It was indicated that the desulfurization rate increased with the increase of radiation time, and the desulfurization rate reached the highest of $79.26 \%$ under radiation time $12 \mathrm{~min}$. After that, desulfurization rate turned to be stable. Waseela Mohamed (Mohamed 2008) studied the effect of microwave irradiation on South African bituminous coals using various alkali solutions, and a percentage reduction in sulphur of approximately $43 \%$ using the caustic solution for coals was possible, and structural characteristics of the coal were apparently unaffected. She also found that treatment with strong $\mathrm{KOH}$ solutions as well as mixed solution of $\mathrm{NaCl}$ and $\mathrm{NaOH}$ improved desulphurisation result in comparison with that of the $\mathrm{NaOH}$ solution alone.

Hayashi et al. (1990) pointed out that the pyritic sulphur may be removed by partial oxidation, chlorination, hydrogenation or reaction with alkali liquor while the organic sulphur may be removed only by molten alkali. Studies have shown that the main functions of microwaves in removing the organic sulphur in coal using molten alkali are that: the coal will be softened into a sticky fluid when it is heated to a certain temperature $(573-623 \mathrm{~K})$; this state of coal influences the mass transfer of molten alkali, and the microwave irradiation can help the molten alkali enter the coal matrix of this state and react with the organic sulphur in coal.

\subsubsection{Desulfurization by microwaves combined with oxidant}

Zhao et al. (2002) treated the coal in acetic acid and hydrogen peroxide oxidation under microwave radiation. The effect of treating conditions, including the size of coal, treatment time, the ratio of acetic acid and hydrogen peroxide and microwave radiation power on the rate of desulfurization were studied by single factor method. The result shows that $60.2 \%$ total sulfur can be removed after treated under the conditions: microwave power $850 \mathrm{~W}$, the concentration of coal slurry $3 / 50(\mathrm{~g} / \mathrm{mL})$, the particle size of coal $\leq 0.23 \mathrm{~mm}$, treatment time is $20 \mathrm{~min}$ and the ratio of acetic acid and hydrogen peroxide 1:1 $(V / V)$. Taking acetic acid and hydrogen peroxide as oxygenant, the desulfurization experiments by microwave were carried out by Chen (2013). It is indicated that the ratio of the acetic acid and $\mathrm{H}_{2} \mathrm{O}_{2}$ has great influence on desulfurization efficiency and cleaned coal yield. When the ratio is $1: 2(\mathrm{~V} / \mathrm{V})$, high desulfurization rate and the cleaned coal yield are obtained. At this ratio, desulfurization rate increases with irradiation time, while bonding index $\mathrm{G}$ extend rapidly to decline over time. Microwave desulfurization combined with peracetic acid can get high desulfurization rate, but the time of desulfurization should not be too long. XPS analysis shows that thiophene sulfur removal rate reached $46.03 \%$ under the optimal oxidation conditions. Zhao et al. (2011) also pointed out that oxidant volume ratio has a great influence on desulfurization, and in his study under the condition of the optimal ratio 1:1, microwave power $700 \mathrm{~W}$, irradiation time $120 \mathrm{~s}$, the desulfurization rate is $49.19 \%$. Meanwhile with nitric acid as oxidant, desulfurization experiments by microwave were carried out (Zhao et al. 2011). $1 \mathrm{~g}$ of coal and $139 \mathrm{~mL}$ nitric acid of $1.4 \mathrm{~mol}$ were mixed together, then exposed to microwave with a frequency of $2,450 \mathrm{MHz}$, power $700 \mathrm{~W}$ for $12 \mathrm{~min}$, and the desulfurization rate of $47.1 \%$ was achieved. In this process, oxidation takes place between pyrite and nitric acid, and sulfur oxides such as sulfate, $\mathrm{SO}_{2}$ were produced, so as to achieve the purpose of removal of inorganic sulfur.

Luo and Wang (2013) studied the desulfurization of coal by ferric sulfate oxidant after the pretreatment by microwave irradiation. The coal sample was exposed to microwave with frequency $2,450 \mathrm{MHz}$, power $800 \mathrm{~W}$ for $5 \mathrm{~min}$ first, and then it was mixed with $1.0 \mathrm{~mol} / \mathrm{L}$ ferric sulfate solution. Under the conditions of reaction temperature $100{ }^{\circ} \mathrm{C}$, reaction time $8 \mathrm{~h}$, concentration coal slurry $10 \%$ (percentage of quality), $62.4 \%$ total sulfur in coal can be removed after oxidation. And this method can reduce the ash content and increase calorific value thereby improving the properties of coal. 


\subsubsection{Desulfurization by microwaves combined with reductant}

There are few reports about this method.

Ferrando (1996) studied the desulphurisation of coal with hydroiodic acid as assistant in a sealed reactor in $\mathrm{H}_{2}$ under microwave irradiation. When the irradiation time was $10 \mathrm{~min}, 99 \%$ pyrite sulphur and $64.7 \%$ of organic sulphur were removed.

Gülhan Güllü Elsamak et al. (2003)studied the desulfurization of lignite using $\mathrm{HI}$ as reductant. The study pointed out that the desulfurization degree of all coal samples will rise with increasing $\mathrm{HI}$ acid concentration. It has been found that HI acid enables the thioether and mercaptan organic sulphur functional groups to rupture from the coal macromolecule structure based on the analysis on desulfurated lignite using FTIR, so as to achieve microwave desulfurization. And it is indicated that sulphur functional groups such as thioether and mercaptan in coal generally need to be removed by strong reductants, such as HI acid. It may be caused by local overheating from microwave radiation. Local overheating, on one hand, helps $\mathrm{HI}$ acid react with thioether and mercaptan organic sulphur; on the other hand, helps HI acid spread toward inside of coal, accelerate coal particles crushing and reduce the desulfurization time.

\subsection{Desulfurization by microwaves combined with ultrasonic}

Desulfurization tests were carried out with different oxidants $\mathrm{H}_{2} \mathrm{O}_{2}+\mathrm{HAc}, \mathrm{FeCl}_{3}+$ EDTA and $\mathrm{MnO}_{2}+$ EDTA under ultrasonic and microwave irradiation by $\mathrm{Mi}$ et al. (2008). The sulfur removal rate increases with increasing extraction time, power of ultrasonic and microwave and the type of oxidants. The $\mathrm{H}_{2} \mathrm{O}_{2}+\mathrm{HAc}$ oxidant has better desulfurization effect than $\mathrm{FeCl}_{3}+$ EDTA and $\mathrm{MnO}_{2}+-$ EDTA. With acetic acid and hydrogen peroxide as oxidant, under conditions: ultrasonic $(540 \mathrm{~W}, 70 \mathrm{~min})$, microwave $(280 \mathrm{~W}, 30 \mathrm{~min})$, the sulfur removal rate of $65 \%$ is obtained, and the removal rates of organic sulphur in different coal samples vary considerably under the same operating conditions, which may be caused by the different chemical forms of organic sulphur in different coals. And with acetic acid and hydrogen peroxide as oxidant, it is indicated (Wei 2011) that thio ethers and thiols are easy to remove, while thiophene sulfur is hard to remove. When it comes to the desulfurization effects of organic solvent extraction for organic sulfur in coal under ultrasonic and microwave irradiation, it is indicated that with tetrachlorethylene as the extraction agent, the organic sulfur in coal was removed apparently with a high recovery rate of clean coal and low loss of calorific value.
It is generally believed that (Wang 2004; Mi et al. 2007; Mi and Kang 2012) ultrasonic waves can widen coal micro-pores and the swelling effect loosens the coal structure to enable the oxidizing agent to easily enter the macromolecular structure of coal thus increasing the contact area between the coal and the oxidizing agent. Desulfurization is promoted by cavitation, impact, micro jet effects of ultrasonic waves, and rapid and selective heating of polar molecules and polarizable molecules by microwaves.

\subsection{Desulfurization by microwaves combined with microorganism}

Wang et al. (2008) applied the microwave technique to coal desulfurization by microorganism. After the coal samples are exposed to microwave irradiation, partial pyrite converts into pyrrhotite which can be more readily leached by A. ferrooxidans thereby improving the effect of desulfurization to some extent, and the total sulfur removal rate reaches $51.3 \%$ in optimal condition. The main characteristic of microorganism desulfurization with a microwave pretreatment lies in that it can significantly shorten the cycle compared with that using A. ferrooxidans only. Ye et al. (2009)achieved removal rate of $52.06 \%$ for total sulphur, $51.61 \%$ for inorganic sulfur and $54.22 \%$ for organic sulphur under conditions of initial $\mathrm{pH} 4.5$, particle size of coal $80-120$ mesh, coal-water fluid concentration $10 \%$ and extraction time of 3 days by applying the desulfurization process using microwaves combined with white-rot fungi.

\subsection{Desulfurization by microwave combined with other methods}

Zheng (2011) studied the removal of organic sulfur in coal with the method of solvent extraction enhanced by microwave. He had the conclusion that the desulfurization rate of coal with PCE and m-cresol as extractant are 39.8, $48.2 \%$ respectively, and the desulfurization rate of coal with PCE and m-cresol as extractant aided by microwave increased by $17 \%$ and $8 \%$ respectively.

Zhu (2008) researched desulfurization of coal by the flotation method with microwave irradiation for pretreatment. The recovery of flotation concentrate can be increased by microwave pretreatment, but only when the appropriate treatment time and intensity are selected, the flotation concentrate ash can be controlled. Microwave can effectively remove the sulfur in coal, and with the extension of microwave irradiation time, the desulfurization rate basically showing an upward trend. 


\subsection{Microwave desulfurization process}

In 1978, Kirkbride (1978) proposed a desulfurization process: the raw coal will be properly pulverized, dried to remove free water, mixed with hydrogen and then treated by microwave radiation. $\mathrm{H}_{2}$ reacts with $\mathrm{S}, \mathrm{N}$ and $\mathrm{O}$ in coal producing $\mathrm{H}_{2} \mathrm{~S}, \mathrm{NH}_{3}$ and water vapor thus achieving the purpose of desulfurization. The coal shall be as dry as possible during the process due to the fact that the water has a strong capacity to absorb microwave energy leading to a very high temperature of the coal and resultant pyrolytic reaction. The hydrogen pressure also has a significant effect on the desulfurization rate. The process is as shown in Fig. 4.

Next year, Kirkbride (1979) proposed the following process when applying for another patent: the coal shall be crushed into a certain particle size and mixed with the saturated hydrocarbon solvent to form a thickened liquid after being dried. The coal enters the reactor under the atmosphere of $\mathrm{H}_{2}$. Within the reactor, there are multiple microwave sources acting on the reactant simultaneously. The three phases, gas, liquid and solid, are separated and desulfurized coal products are obtained after desulfurization reaction. $\mathrm{H}_{2}$ can be recovered for cyclic utilization as well as by-products of $\mathrm{H}_{2} \mathrm{~S}$ and $\mathrm{NH}_{3}$ with the solvent. The process is as shown as in Fig. 5.

In 1978, in Zavitsanos's (and Blriler 1978) patents, the raw coal is pulverized to a particle size less than $5 \mathrm{~cm}$. Under the conditions of $2.45 \mathrm{GHz}$ frequency and the power of $500 \mathrm{~W}$ or more, the inorganic sulfur in coal is decomposed following microwave irradiation for 40-60 s and releases $\mathrm{H}_{2} \mathrm{~S}$ and $\mathrm{SO}_{2}$ and elemental sulfur forms on the surface of the coal. This method can remove $50 \%$ sulphur.
In 1987, Kelland (Kelland 1987) in a patent used the microwave selective thermolysis to decompose pyrite. The troilite and pyrrhotite produced are used as catalyst to remove the organic sulphur. Flocculant can be added to enable other miners to be combined with pyrite, and they will be removed through magnetic separation so as to reduce the ash content. The process is as shown as in Fig. 6.

In 1995, Frank (Marhanka 1995), in his patent, mixed the coal with adsorbent (alumina particles). Exposed to microwave irradiation for a period of time, the sulphur escaped in the form of gas and was absorbed by the adsorbent. Then the coal and adsorbent were separated. The whole process is divided into four stages: microwave heating, coal mixing with adsorbent, coal separating with

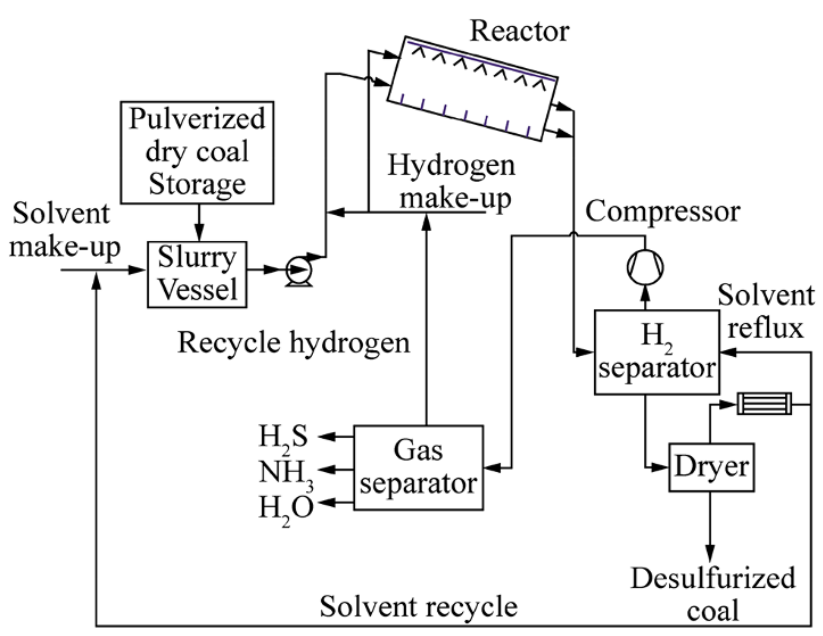

Fig. 5 Process diagram of Kirkbride's patent 2

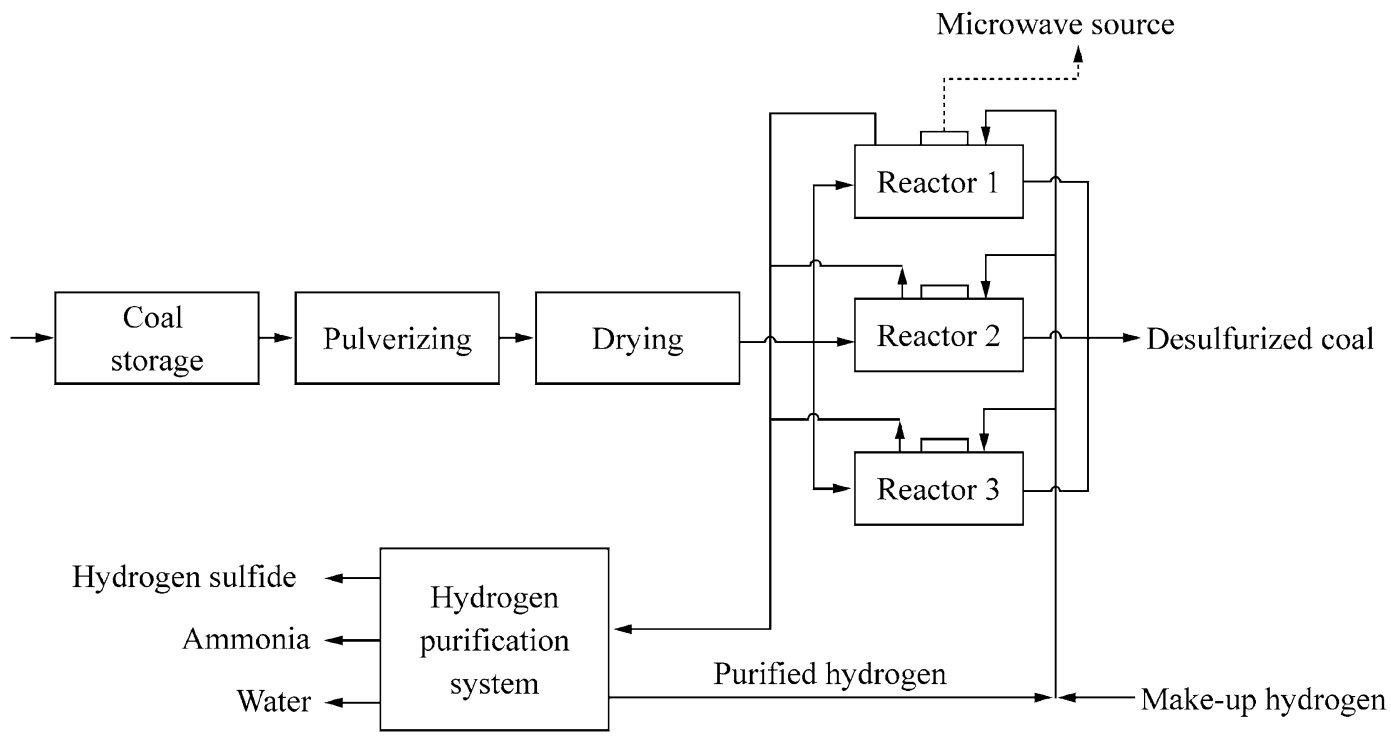

Fig. 4 Process diagram of Kirkbride's patent 1 


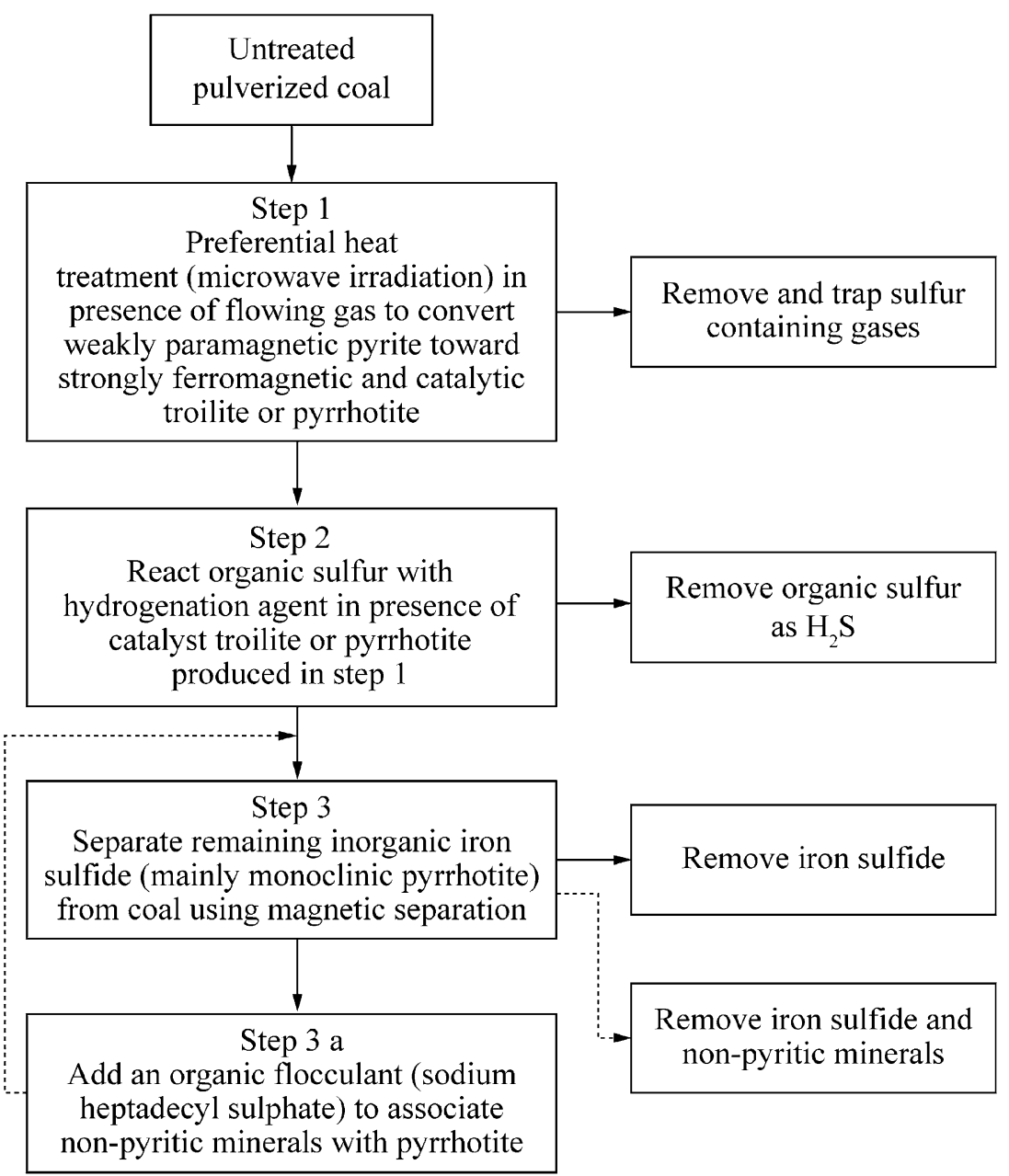

Fig. 6 Process diagram of Kelland's patent

adsorbent and sulfurous gas treatment. The desulfurization rate of the test coal reaches $75 \%$ after it is exposed to irradiation of $800 \mathrm{~W} 2,000-4,000 \mathrm{MHz}$ microwaves for 6 min.

In a patent of $\mathrm{Hu}$ et al. (2008), the coal was pulverized into a particle size less than $0.3 \mathrm{~mm}$, mixed with additives (caustic solution or hydrogen peroxide-acetic acid mixed solution), put into the water and stirred well. After exposed to microwave radiation for 2-10 $\mathrm{min}$, the desulfurized coal is obtained through separation. By using this method, the desulfurization rate of Shandong Guohong coal can reach $62.5 \%$, the desulfurization rate of Xuecheng Shanjiazhong fat coal can reach $50.9 \%$; the XPS photoelectron spectroscopy shows that this method can effectively remove the pyrite in sulphur coal and can also remove the organic sulphur to some extent.

In 2011, Yaniv and Livneh (2011) et al. mentioned in the patent that the heat treatment by microwave can be used to convert the pyrite in coal into pyrrhotite and locally dry lump coal in a short period of time. This treatment contributes to subsequent desulphurization using a low-intensity dry-type magnetic separation process.

In 2012, Zheng et al. proposed in the patent (Zheng et al. 2012) that the coal passes through a microwave cavity containing $\mathrm{N}_{2}$ at a frequency of $820-2,700 \mathrm{MHz}$ and a power of 5-120 kW for dehydration and desulphurization under a lower temperature of not more than $110{ }^{\circ} \mathrm{C}$ to reduce the water content in coal to $5 \%$ below and the sulphur content to $0.02 \%$ below. It is characterized by reasonable structural design, high production efficiency, and proper safety.

In 2013, in a patent (Zhou et al. 2013a, b), Zhou Min et al. improved the coking process and added a microwave pretreatment after the coal blending process. The coal blended for coking passes through a microwave reaction cavity at a frequency of $300 \mathrm{MHz}-300 \mathrm{GHz}$ for treatment. In this pretreatment process, the coal layer thickness and 
length of stay in the reaction cavity should be controlled, the sulphur-containing gases within the cavity should be exported timely, and it should be ensured that the temperature of the coal sample after pre-treatment was $150-250{ }^{\circ} \mathrm{C}$. It can achieve dehydration, and desulphurization of the coal blended, increase its bulk density, elevates the output of a single furnace, and reduce the time required for coking.

In a patent (Kong and Qiu, 2013), Kong Fanjin et al. performed negative pressure treatment for raw coal in a vacuumized chamber at $100{ }^{\circ} \mathrm{C}$ below in combination with the microwave heating to rapidly remove vaporizable sulphur-containing substance in coal based on the rule that the boiling point of organic sulphur in coal declines with the decrease of pressure. The vaporized sulphur-containing substance and the $\mathrm{H}_{2} \mathrm{~S}, \mathrm{SO}_{2}$, elemental sulfur vapor released by inorganic sulfur after decomposition were taken away by the action of vacuum draw. The pyrite was converted into pyrrhotite and troilite under the effect of microwave, which contributes to subsequent magnetic separation. In addition, negative pressure treatment in a low temperature does no damage to the structure, cohesiveness, and calorific value of coal.

Zhao Jian et al., in the patent (Zhao et al. 2013), divided the microwave reaction cavity into two chambers along the direction of coal delivery. The coal first passes through the first chamber at a microwave power of $40 \mathrm{~kW}$ and a frequency of $915 \mathrm{MHz}$ to raise the temperature rapidly for impurities removal; then it enters the second chamber with frequency of $915 \mathrm{MHz}$ to preserve heat under a lower power $(20 \mathrm{~kW})$ for further impurities removal. Meanwhile, the gas within the cavity is drawn timely and $\mathrm{N}_{2}$ and spray water are inlet to prevent combustion due to over-temperature of coal during irradiation. Finally, the method achieves coal drying and desulphurization with high efficiency of impurity removal and satisfactory result.

In addition, it is reported that General Electric Company (GE) invented a method of microwave desulfurization for coal, where the coal is pulverized into a particle size between 150 and $590 \mu \mathrm{m}$, mixed with caustic sodium solution, dehydrated to some extent and exposed to microwave irradiation for 30-60 s under the atmosphere of nitrogen. The pyritic sulphur and organic sulphur in coal convert into water-soluble sulphide and are removed by washing. In the laboratory test, double irradiations, washings and repeated steps can remove $90 \%$ of the pyritic sulphur and $50 \%-70 \%$ of the organic sulphur. The heating value of coal hardly varies. The process for each microwave treatment is: the coal is mixed with caustic alkali, dried, exposed to microwave irradiation, washed by water and acid respectively.

\section{Challenges and countermeasures for microwave desulfurization technique}

\subsection{Problems and challenges}

The microwave technique has been applied in coal desulfurization for more than thirty years and certain progress has been made. However, the problems exposed in the technique of coal desulfurization by microwaves shall also draw the attention of scientific research personnels. The main problems of microwave desulfurization technique currently include:

(1) There is lack of enough understanding of sulphurcontaining functional groups, especially organic sulphur functional groups in coal due to the complexity of coal macromolecular structure and limitation of the existing testing equipment and means. As a result, it is impossible to specifically test the dielectric properties of sulphur-containing functional groups in coal and further understand the rules of their responses to microwave irradiation thus influencing the desulfurization effect.

(2) The microwave desulfurization mechanism is expected to be studied further, which is very important for the practice of removing organic sulphur in coal. Microwaves, in addition to a thermal-effect, also have a non-thermal effect caused by its own characteristics. It is generally accepted that microwaves are able to remove the sulphur content in coal due largely to their thermal effect. Nevertheless, the most common microwaves with a frequency of $2.45 \mathrm{GHz}$ are not enough to rupture $\mathrm{Fe}-\mathrm{S}$ bond and $\mathrm{C}-\mathrm{S}$ bond owing to the fact that their energy are only $1.02 \times 10^{-5} \mathrm{eV}$. Moreover, the mechanism of removing organic sulphur by microwaves has only been explained generally and not thoroughly yet.

(3) The problem of secondary pollution caused by microwave pyrolysis desulfurization; further studies about such problems as the effects of assistants added on the coal properties, the recycle of assistants, and the utilization of the byproducts $\left(\mathrm{H}_{2} \mathrm{~S}, \mathrm{SO}_{2}\right.$ etc.) shall be conducted.

(4) As a whole, the microwave desulfurization technique is at its laboratory study stage. There may exist small-scale industrial applications somewhere but the desulfurization effect is not ideal. On one hand, the economic benefit remains low for such reasons as limitation of operating frequency of microwave equipment, large difficulties and investment in designing such equipment etc.; on the other hand, although certain effects have been achieved in 
laboratories, some experiment conditions are hard to be achieved in industrial applications. The key technology of microwave desulfurization shall be developed further and vigorously.

\subsection{Countermeasures}

In response to the problems above, the development of microwave desulfurization technique may be accelerated from the following aspects:

(1) Attach importance to studies on occurrence characteristics such as constitution, distribution etc. of sulphur-containing functional groups in coal (particularly organic sulphur). There are two ways used for testing the sulphur-containing functional groups in coal, i.e. destructive testing and non-destructive testing. Hence, the sulphur-containing functional groups shall be studied by a multi-scaled and highlevel means. Meanwhile, other new testing methods shall also be explored to improve and supplement the studies on the sulphur-containing functional groups in coal.

(2) Strengthen fundamental researches on the microwave desulfurization technique. Model compounds may be used to test the corresponding dielectric properties of sulphur in coal, study its rules of physical and chemical responses to microwaves and microwave energy and further discuss the mechanism for removing sulphur in coal with reference to experience of other desulfurization techniques.

(3) Study on special microwave desulfurization equipment. Proper design of microwave desulfurization equipment is the decisive factor to achieve success. Making a survey on the microwave equipment currently used in coal desulfurization studies, some are microwave ovens used in our daily life and some are preferably modified ones while microwave output equipment specially designed for microwave desulfurization is less common. Therefore, special equipment shall be developed based on microwaves characteristics and microwaves transmission characteristics, which is significant to development of the microwave desulfurization technique.

(4) Innovate on the microwave desulfurization technique to explore new microwave desulfurization methods. Sulphur-containing bonds in coal may be ruptured selectively utilizing various microwave frequencies so as to remove the sulphur in coal, which has draw attention from experts and scholars; in addition, microwave chemistry is more and more popular among researchers and introduction of microwave chemistry to the field of coal desulfurization is another major research subject.

\section{Conclusions}

The microwave desulfurization technique has been brought to people's attention for its characteristics such as good desulfurization effect, quickness, mild and controllable conditions etc. The paper summarizes the applications of microwave technique in the coal desulfurization field and the research progress achieved in detail. There are controversies on the principle of microwave desulfurization, and microwave thermal effects resulted from the characteristics of microwave dielectric heating are more acceptable compared with non-thermal effect in which view direct interactions between the microwave electromagnetic field and reactant molecules are proposed. There is still lack of research on the equivalent dielectric constant of coal desulfuration system under temperature-changing conditions, and the responses of coal and sulphur-containing constituents to microwave electromagnetic field are still unclear. Many methods are developed to achieve a better desulfurization effect, such as directly microwave desulfurization, combining with other methods like magnetic separation, chemical method (adding chemical additives such as acid, alkali, oxidant, reductant), ultrasonic, microbiology.

Unclear mechanism for microwave desulfurization and uncertain qualitative and quantitative analyses on sulphurcontaining functional groups in coal constrain further development of the microwave desulfurization technique. With development of science and technology, involvement of a large number of scientific research personnel and introduction of advanced testing equipment, the microwave desulfurization technique will necessarily make significant progress through innovation.

Open Access This article is distributed under the terms of the Creative Commons Attribution License which permits any use, distribution, and reproduction in any medium, provided the original author(s) and the source are credited.

\section{References}

Agilent (2006) Basics of Measuring the Dielectric Properties of Materials, Application note

Alam HG, Moghaddam AZ, Omidkhah MR (2009) The influence of process parameters on desulfurization of Mezino coal by HNO3/ $\mathrm{HCl}$ leaching. Fuel Process Technol 90(1):1-7

Al-Harahsheh M, Kingman SW (2004) Microwave-assisted leaching: a review. Hydrometallurgy 73(3-4):189-203 
Al-Harahsheh M, Kingman S, Bradshaw S (2006) The reality of nonthermal effects in microwave assisted leaching systems? Hydrometallurgy $84(1-2): 1-13$

Antonio C, Deam RT (2007) Can"microwave effects" be explained by enhanced diffusion? Phys Chem Chem Phys 9(23):2976-2982

Arnaud CH (2009) Microwave chemistry's thermal effect. Chem Eng News 87:43

Balanis CA, Shepard PW, Ting FTC (1980) Anisotropic electrical properties of coal. Geosci Remote Sens, IEEE Trans 18(3):250-256

Boykov ND (2006) Measurements of the electrical properties of coal measure rocks. Doctor's thesis, West Virginia University

Cai CC (2013) Responses laws of high organosulfur coking coal to microwave. Doctor's thesis, Anhui University of Technology

Chatterjee I, Misra M (1990) Dielectric properties of various ranks of coal. J Microw Power Electromagn Energy 25(4):224-229

Chen HB (2013) Research on the microwave-assisted desulfurization of Xinyu coking coal. Master's thesis, China University of Mining and Technology

Chen XX, Xu P, Xia ZN (2009) Methods for non-thermal microwave effects in microwave assisted organic synthesis. Chem 8:674-680

Chen XY, Lan XZ, Zhang QL (2011) Experimental study on extraction of vanadium from stone coal by microwave pretreatment. Adv Mater Res 148-149:1518-1522

Cheng R, Qiu JH (2002) Application of mossbauger spectrocopy in the experiment of coal desulfurization by microwave radiation. Environ Eng 20(2):34-36

Chu JP (2011) Study of the relationship between the degree of coal and high voltage slected. Coal Eng 7:100-101

Clark DE, Folz DC, West JK (2000) Processing materials with microwave energy. Mater Sci Eng A 287(2):153-158

de la Hoz A, Díaz-Ortiz A, Moreno A (2005) microwaves in organic synthesis thermal and non-thermal microwave effects. Chem Soc Rev 34(2):164-178

de la Hoz A, Díaz-Ortiz A, Moreno A (2007) Review on non-thermal effects of microwave irradiation in organic synthesis. Microw Power Electromagn Energy 41(1):44-64

Didier S (2006) Microwaves in organic synthesis, 2nd edn. Wiley$\mathrm{VCH}$, Weinheim

Dong SY (1990) Microwave measurement technique. Beijing Institute of Technology Press, Beijing

Elsamak GG, Öztaş NA, Yürüm Y (2003) Chemical desulfurization of Turkish Cayirhan lignite with HI using microwave and thermal energy. Fuel 82(5):531-537

Feng XM, Chen JL (2007) Study on electromagnetic properties of anthracite and soft coal in microwave field. Taiyuan Univ Technol 38(5):405-407

Ferrando AC (1996) Coal desulphurisation with hydroiodic acid and microwaves. Fuel Energy Abstr 37(5):333

Forniés-Marquina JM, Martín JC, Martínez JP (2003) Dielectric characterization of coals. Can J Phys 81(3):599-610

Gao MH, Zhang XX, Chen QR (2007) Dielectric constant and tribocharging of minerals companying with coal. China Mining Mag 16(8):106-109

Gao JS, Lu J, Wang J (2010) Pollution and control in the process of coal chemical industry. Chemical Industry Press, Beijing

Ge LC, Zhang YW, Wang ZH, Zhou JH, Cen KF (2013) Effects of microwave irradiation treatment on physicochemical characteristics of Chinese low-rank coals. Energy Convers Manag 71:84-91

Gomaa AI, Sedman J, Ismail AA (2013) An investigation of the effect of microwave treatment on the structure and unfolding pathways of beta-lactoglobulin using FTIR spectroscopy with the application of two-dimensional correlation spectroscopy (2D-COS). Vib Spectrosc 65:101-109

Hakala JA, Stanchina W, Soong Y (2011) Influence of frequency, grade, moisture and temperature on Green River oil shale dielectric properties and electromagnetic heating processes. Fuel Process Technol 92(1):1-12

Han LC, Li E, Guo GF, Zheng H (2013) Application of transmission/ reflection method for permittivity measurement in coal desulfurization. Prog Electromagn Res Lett 37:177-187

Hayashi J, Oku K, Kusakabe K (1990) The role of microwave irradiation in coal desulphurization with molten caustics. Fuel 69(6):739-742

He JM, Wang SX, Lu YQ (2001) Coal sulfur dioxide pollution control technical manuals. Chemical Industry Press, Beijing

Horikoshi S, Serpone N (2011) Microwave frequency effect(s) in organic Chemistry. Mini-Rev Org Chem 8(3):299-305

$\mathrm{Hu}$ BX, He QH, Cai J (2008) Method for desulfurizing coal by microwave. Chinese Patent: 10023226.8

Huang KM, Yang XQ (2006) Advanced of non-thermal effect of microwave accelerating chemical reaction. Prog Nat Sci $16: 273-279$

Huang KM, Yang XQ, Hua W (2009) Experimental evidence of a microwave non-thermal effect in electrolyte aqueous solutions. New J Chem 33(7):1486-1489

Jones DA, Lelyveld TP, Mavrofidis SD (2002) Microwave heating applications in environmental engineering: a review. Resour Conserv Recy 34(2):75-90

Jorjani E, Rezai B, Vossoughi M (2004) Desulfurization of Tabas coal with microwave irradiation/peroxyacetic acid washing at 25,55 and $85^{\circ} \mathrm{C}$. Fuel 83(7-8):943-949

Kalra A (2006) Dewatering of fine coal slurries by selective heating with microwaves. Doctor's thesis, West Virginia University

Kappe CO, Stadler A, Dallinger D (2005) Microwaves in organic and medicinal chemistry. Wiley-VCH, Weinheim

Kawatra SK, Eisele TC (2001) Coal desulfurization: high-efficiency preparation methods. Taylor \& Francis, New York

Kelland DR (1987) Method for desulfurization of coal. US Patent: 4678478

Kirkbride CG (1978) Sulphur removal from coal. US Patent: 4123230

Kirkbride CG (1979) Process for removing sulfur from coal. US Patent: 4148614

Kong FJ, Qiu CA (2013) Continuous and rapid system of desulfurization from raw coal for clean coal. Chinese Patent: 201220 240677.9

Krupka J (2006) Frequency domain complex permittivity measurements at microwave frequencies. Meas Sci Technol 17(6):55-70

Lester E, Kingman S, Dodds C (2006) The potential for rapid coke making using microwave energy. Fuel 85(14-15):2057-2063

Li XC, Nie BS, Liu WB (2012) Experimental study on the impact of temperature on coal electric parameter. Adv Mater Res 524-527:431-435

Lin L, Chen J, Xu Z (2009) Removal of ammonia nitrogen in wastewater by microwave radiation: a pilot-scale study. Hazard J Mater 168(2-3):862-867

Luo DC, Wang W (2013) Study on desulfurization of coal by ferric sulfate oxidation in combination with microwave pretreatment. Miner Eng Res 28:70-74

Luo YF, Li WH, Jiang Y (2005) Distribution of sulfur in coals of China. Coal Convers 28(3):14-18

Ma SC, Yao JJ, Jin X (2011) Progress for thermal and non-thermal effects of microwave chemistry. Chem 74(1):41-46

Marhanka FD (1995) Method and apparatus for desulfurizing coal. US Patent: 5393311

Marland S, Han B, Rowson NA, Merchant AJ (1998) Microwave embrittlement and desulphurization of coal. Acta Montanistica Slovaca 3(3):351-355

Marland S, Han B, Merchant A, Rowson N (2000) The effect of microwave radiation on coal grindability. Fuel 79(11): $1283-1288$ 
Marland S, Merchant A, Rowson N (2001) Dielectric properties of coal. Fuel 80(13):1839-1849

Meikap BC, Purohit NK, Mahadevan V (2005) Effect of microwave pretreatment of coal for improvement of rheological characteristics of coal-water slurries. Colloid Interface Sci 281(1): 225-235

Meng L (2001) Experimental study on the electrical parameters of coal. Master's thesis, Henan Polytechnic University

Mi J, Kang J (2012) Desulfurization of Lu'an coal by ultrasonic and microwave. Adv Mater Res 512-515:2494-2499

Mi J, Ren J, Wang JC, Bao WR, Xie KC (2007) Ultrasonic and microwave desulfurization of coal in tetrachloroethylene. Energy Sources Part A 29(14):1261-1268

Mi J, Ren J, Wang JC (2008) Ultrasonic and microwave co-enhanced oxidative desulfurization of organic sulphur from coal. China Coal Soc 33(4):435-438

Misra M, Kumar S, Chatterjee I (1991) Flotability and dielectric characterization of the intrinsic moisture of coals of different ranks. Coal Prepar 9(3-4):131-140

Mohamed W (2008) Desulfurization of South African coal using low power microwave energy. Doctor's thesis, University of the Witwatersrand Johannesburg

Mursito AT, Hirajima T, Sasaki K (2011) Alkaline hydrothermal deashing and desulfurization of low quality coal and its application to hydrogen-rich gas generation. Energy Convers Manag 52(1):762-769

Mutyala S, Fairbridge C, Pare JRJ (2010) Microwave applications to oil sands and petroleum: a review. Fuel Process Technol 91(2):127-135

Nelson SO (2010) Fundamentals of dielectric properties measurements and agricultural applications. Microw Power Electromagn Energy 44(2):98-113

Peng ZW, Hwang JY, Kim BG (2012) Microwave absorption capability of high volatile bituminous coal during pyrolysis. Energy Fuels 26(8):5146-5151

Reddy PM, Huang YS, Chen CT (2013) Evaluating the potential nonthermal microwave effects of microwave-assisted proteolytic reactions. J Proteomics 80:160-170

Remya N, Lin JG (2011) Current status of microwave application in wastewater treatment: a review. Chem Eng J 166(3):797-813

Rowson NA, Rice NM (1990a) Magntic enhancement of pyrite by caustic microwave treatment. Miner Eng 3(3-4):355-361

Rowson NA, Rice NM (1990b) Desulphurisation of coal using low power microwave energy. Miner Eng 3(3-4):363-368

Royaei MM, Jorjani E, Chehreh Chelgani S (2012) Combination of microwave and ultrasonic irradiations as a pretreatment method to produce ultraclean coal. Int J Coal Prep Util 32(3):143-155

Sahoo BK, De S, Meikap BC (2011) Improvement of grinding characteristics of Indian coal by microwave pre-treatment. Fuel Process Technol 92(10):1920-1928

Santra M (2005) Estimation of complex permittivity of arbitrary shape and size dielectric samples using cavity measurement technique at microwave frequencies. IEEET Microw Theory 53(2):718-722

Schmink JR, Leadbeater NE (2009) Probing"microwave effects" using Raman spectroscopy. Org Biomol Chem 7(18):3842-3846

Sheng YH (2013) Study on enhancing coal desulfurization with combination of microwave radiation and aqueous sodium hydroxide. Master's thesis, China University of Mining and Technology

Sheng YH, Tao XX, Xu N (2012) Experimental study on infuence factors of coal desulfurization under microwave irradiation. China Coal 38(4):80-82

Sui JC, Qiu JH, Cheng R (2004) Experimental study of the influence of desulfurization by microwave radiation. Huazhong Univ Sci Tech 32(6):93-95
Sun XJ, Su YZ, Jin FM (2000) A study on non-thermal efficiency of microwave chemical reaction. Jiangsu Inst of Petrochem. Technol 12(3):42-45

Tang WQ, Lu JJ, Zhang H (2006) Non-thermal efficiency of microwave during devulcanization. Rubber Ind 53(8):453-456

Tao YJ, Luo ZF, Zhao YM, Tao D (2006) Experimental research on desulfurization of fine coal using an enhanced centrifugal gravity separator. J China Univ Min Technol 16(4):399-403

Temel HA, Bozkurt V, Ayhan FD (2010) Desulfurization and deashing of Adiyaman-Gölbaşi lignite by flotation. Energy Sources, Part A 32(8):727-743

Thostenson ET, Chou TW (1999) Microwave processing: fundamentals and applications. Compos Part A 30(9):1055-1071

Tian BN, Yang DS, Tang JM (2002) Some problems of the transmission/reflection method for measuring complex permittivity of materials. Chin J Radio Sci 17:10-15

Uslu T, Atalay Ü (2003) Microwave heating of coal for enhanced magnetic removal of pyrite. Fuel Process Technol 85(1):21-29

Uslu T, Atalay Ü, Arol AI (2003) Effect of microwave heating on magnetic separation of pyrite. Colloids Surf A 225(1-3):161-167

Venkatesh MS, Raghavan GSV (2005) An overview of dielectric properties measuring techniques. Can Biosyst Eng 47:715-730

Waanders FB, Mohamed W, Wagner NJ (2009) Changes of pyrite and pyrrhotite in coal upon microwave treatment. Proceeding of the International Conference on the Applications of the Mössbauer

Wang QZ (1982) The electric resistivity and relative dielectric constant of coal. Coal Mine Safety Technol 1:19-26

Wang JC (2004) Removing sulfur in coal by extraction and oxidation under ultrasonic and microwave. Doctor's thesis, Taiyuan University of Technology

Wang XT (2006) Broad-band measurement method for electromagnetic property parameters of microwave and millimeter wave. Equip Environ Eng 3(3):33-36

Wang J, Yang JK (1994) Behavior of coal pyrolysis desulfurization with microwave energy. Fuel 73(2):155-159

Wang CG, Xiang D, Jiang WJ (2008) Preliminary study on biodesulfurization technology of coal in combination with microwave pretreatment. Chin J Environ Eng 2(3):408-412

Waters KE, Rowson NA, Greenwood RW (2007) Characterising the effect of microwave radiation on the magnetic properties of pyrite. Sep Purif Technol 56(1):9-17

Wei RT (2011) Study on the removal of sulfur in coal under ultrasonic and microwave. Master's thesis, Taiyuan University of Technology

Weng SH, Wang J (1992) Exploration on the mechanism of coal desulfurization using microwave irradiation/acid washing method. Fuel Process Technol 31(3):233-240

Xia ZX, Liu CJ, Yan LP (2004) Progress in microwave chemistry research and applications. Chem Res Appl 16(4):441-444

Xia WC, Yang JG, Liang C (2013) Effect of microwave pretreatment on oxidized coal flotation. Powder Technol 233:186-189

Xiao JK (1985) The effects of mineral composition and structure on dielectric constants. Acta Miner Sin 5(4):331-337

Xu HW (2005) Measurement and test of seam electric parameter and study on relationship between seam electric parameter and coal petrology characteristics. Coal Sci Technol 33(3):42-46

$\mathrm{Xu}$ LJ, Xian XF, Li XH (1998) An experimental study on the permittivity of Baijiao Coal in alternating electric field. Chongqing Univ 21(3):6-10

Yang XQ, Huang KM (2006) Investigation of key problems of interaction between microwave and chemical reaction. Chin $\mathbf{J}$ Radio Sci 21(5):802-809

Yang JK, Ren JL (1988) Microwave desulfurization of coal and its relationship with the dielectric properties of the sample. East China Inst Chem Ind 14(6):713-718 
Yang JY, Ye XJ, Qin HW, Miao FY (2013) Progress in research of coal micro-organism leaching desulfurization. Min Mach 41(5):5-8

Yaniv I, Livneh BZ (2011) Method and system for separation of contaminants from coal. Chinese Patent: 200880130872.2

Ye YH, Wang XD, Jiang WJ (2009) Experimental study on microwave-assisted white rot fungus desulfurization of coal. Chin J Environ Eng 3(7):1303-1306

Yin YB (2003) Introduction to microwave desulfurization of coal. Coal Prep Technol 4:54-55

Zavitsanos PD, Blriler KW (1978) Process for coal desulphurizafion. US Patent: 4076607

Zhang DC (2005) Microbial removal of pyrite sulfur in coal. Hefei Industrial University Press, Hefei

Zhao QL, Zheng JM, Duan ZH (1996) Microwave desulphurization of coal. Coal Convers 19(3):9-13

Zhao JL, Zhang YY, Chen QY (2002) The desulfurization of high organic sulfur coal by oxidation under microwave radiation. Microwaves 18(2):80-84

Zhao HX, Li Y, Qu YH, Duan ZH, Zhang JH, Liu J (2011) Experimental study on microwave desulfurization of coal. Proceeding of 2011 International Conference on Materials for Renewable Energy \& Environment (ICMREE), 2:1706-1710
Zhao J, Sun WB, Li GY (2013) A system for clean coal. Chinese Patent: 201220743062.8

Zheng LH (2011) Organic sulfur removal from high sulfur coal by extraction. Master's thesis, Hunan University of Science and Technology

Zheng YH, Liu C, Yao T (2012) System for low temperature dehydration and desulfurization from coal using microwave. Chinese Patent: 201210287483.9

Zhou M, Wang HY, Zong ZJ (2013a) Method and system for coking using microwave pretreatment desulfurization. Chinese Patent: 201310024082.9

Zhou M, Yang X, Song LQ (2013b) Research progress of coal microwave desulphurization. J Henan Polytech Univ 32(6):760-763

Zhu D (2008) Effect of ultrasonic and microwave on flotation and desulfurization. Master's thesis, Anhui University of Science and Technology

Zubkova V, Prezhdo V (2006) Change in electric and dielectric properties of some Australian coals during the processes of pyrolysis. Anal Appl Pyrolysis 75(2):140-149 